\title{
On the importance of analyzing flood defense failures
}

\author{
Işıl Ece Özer ${ }^{1}$, Myron van Damme ${ }^{1, a}$, Timo Schweckendiek ${ }^{1,2}$ and Sebastiaan N. Jonkman ${ }^{1}$ \\ ${ }^{1}$ Delft University of Technology, Department of Hydraulic Engineering, Delft, Netherlands \\ ${ }^{2}$ Deltares, Unit Geo-engineering, Delft, Netherlands
}

\begin{abstract}
Flood defense failures are rare events but when they do occur lead to significant amounts of damage. The defenses are usually designed for rather low-frequency hydraulic loading and as such typically at least high enough to prevent overflow. When they fail, flood defenses like levees built with modern design codes usually either fail due to wave overtopping or geotechnical failure mechanisms such as instability or internal erosion. Subsequently geotechnical failures could trigger an overflow leading for the breach to grow in size Not only the conditions relevant for these failure mechanisms are highly uncertain, also the model uncertainty in geomechanical, internal erosion models, or breach models are high compared to other structural models. Hence, there is a need for better validation and calibration of models or, in other words, better insight in model uncertainty. As scale effects typically play an important role and full-scale testing is challenging and costly, historic flood defense failures can be used to provide insights into the real failure processes and conditions. The recently initiated SAFElevee project at Delft University of Technology aims to exploit this source of information by performing back analysis of levee failures at different level of detail. Besides detailed process based analyses, the project aims to investigate spatial and temporal patterns in deformation as a function of the hydrodynamic loading using satellite radar interferometry (i.e. PS-InSAR) in order to examine its relation with levee failure mechanisms. The project aims to combine probabilistic approaches with the mechanics of the various relevant failure mechanisms to reduce model uncertainty and propose improvements to assessment and design models. This paper describes the approach of the study to levee breach analysis and the use of satellites for breach initiation analysis, both adopted within the SAFElevee project.
\end{abstract}

\section{Introduction}

The majority of the global population is located in flood prone coastal and delta areas. History thereby shows that the consequences of flood events can be severe. The flooding of the South-West of the Netherlands and South-East of England in 1953 resulted in a large number of fatalities and substantial economic losses. A recent example of a flood with large economic damage is that of Queensland Australia in January 2011 with damages exceeding \$30 billion [1]. Between 1998 and 2009, 213 floods occurred in Europe which caused for economic, social, and environmental damage, and 1126 deaths [1].

As an attempt to improve flood risk management, the EU Floods Directive 2007/60/EC was developed and published in October 2007 [2]. The aim of the EU Floods directive is to reduce and manage flood risk with respect to public health, environment, cultural heritage, and economic activity. EU member states are required to perform a preliminary assessment of areas at risk of flooding. Flood risk maps were completed for these areas by 2013 , and prevention, protection and preparedness plans were developed for these areas by 2015 [2]. To assess the areas at risk of flooding and the possible severity of the floods, flood spreading models have been

\footnotetext{
${ }^{a}$ Corresponding author: M.vanDamme@tudelft.nl
}

developed and included into river flow models and coastal models. For accurate modelling of the spreading of a flood, the flow rate of water entering a flood area needs to be accurately predicted. When failure of a levee causes an area to flood, the flow rate of inflowing water is determined by the size of the breach, and the growth rate of the breach with respect to the rate of change of the water level in the river. Empirical breach relationships have been developed using available data on breaches [3]. However, the large variety in loading conditions on levees, levee design, and failure modes, combined with limited data available on failed levees, make empirical models inaccurate. Unfortunately, developers of empirical models often do not comment on the inherent inaccuracy of the models. Hence, studies related to the uncertainty in flood risk ignore the inherent inaccuracy of breach models and focus solely on the impact of variation in input parameters on the accuracy of output values. This then leads to the erroneous conclusion that breach models make only a small contribution to the overall inaccuracy in flood risk, whereas the opposite could be true [4]. Although more accurate predictions of flood volumes could be obtained from process-based breach models, it should be noted that model inaccuracies nevertheless arise from a lack of understanding of the breach processes. 
A second aspect for a good flood risk analysis is to accurately determine the probability of failure. This often follows from a stress strength analysis. Hindcasting of failures have often shown that levees were either stronger or weaker than initially anticipated. In the case of weaker the risk levels are underestimated which could be problematic. In case levees appear to be stronger than initially anticipated the consequences can be minor but nevertheless lead to a strengthening of a levee where none would have been needed. For either case further insights into the processes that lead to failure and the consequences of failure would be beneficial. Despite extensive research on failure mechanisms such as instability, piping or overflow-induced breaching, considerable uncertainties in failure modelling and prediction remain.

Especially in coastal and delta areas, continuous monitoring the condition of levees is crucial as well as difficult. The current investigation methods are mostly subjective and infrequent [5][6]. Innovative and costeffective deformation monitoring of water defense systems does not only enable to understand failures but also to perform their appropriate and on-time maintenance. A better investigation of levee performance and failure modes can allow us to achieve more effective levee design and reinforcements. Using satellite radar interferometry can complement existing approaches for assessing levee deformation and failure investigations (e.g. expensive field tests) at relatively low cost.

The SAFElevee project at Delft University of Technology focuses on levee performance and failure, and analyses the interrelated processes of (initial) failure of a levee and breach development, both at a systemmacro scale as well as for individual failures (Figure 1). It emphasizes to improve the understanding of breach formation and breach initiations processes. At the same time, one of the project objective is to use methods of satellite remote sensing in order to reveal how continuous levee monitoring could be used to predict real failures in extreme conditions. This paper aims to outline the actions taken under the SAFElevee project and thereby gives an overview of the state of the art research to date.

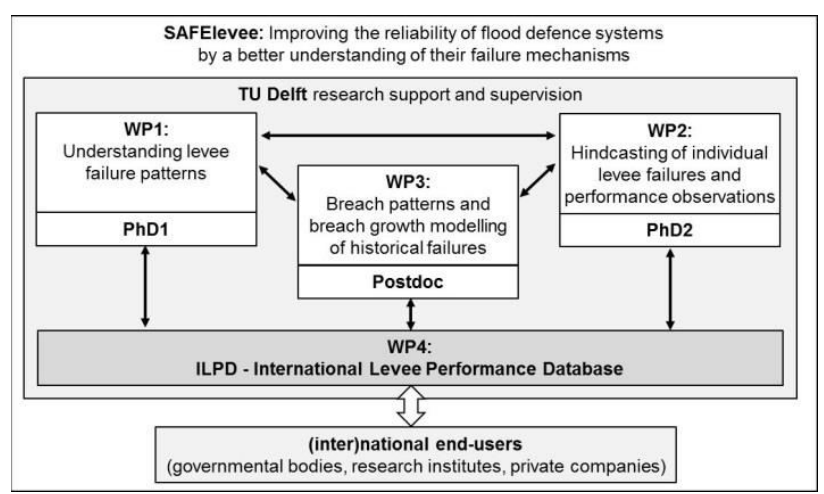

Figure 1. The structure of the SAFElevee project

To illustrate some of the aspects covered by the project, Section 2 outlines the International Levee Performance Database that is under development as part of the project. Section 3 comments on the challenges that the SAFElevee project aims to address in studying the breach processes, and Section 4 comments on the use of radar satellites to correlate loading conditions with deformations and past failures to identify locations where geotechnical failures are likely to occur. Recommendations is given in the Section 5 by integrating also future research directions.

\section{International Levee Performance Database (ILPD)}

Systematic documentation and analyses of international levee performance data enables the development of accurate techniques for the innovative and cost-effective designs of flood defense systems. The understanding of failures mechanisms can be significantly improved by the analysis of failure patterns, hindcasting of historical levee failures, and other performance observations such as monitored near-failures or field observations during extreme loading [7]. Individual efforts have been undertaken to document failures of levees after disasters (e.g. [8][9][10]), but no systematically gathered large-scale datasets are available for thorough scientific research. This results in a lack of calibration and validation data for levee failure and performance models.

Several databases have already been developed for levee dam breaches in table format [11][12]. Characteristic of these databases is that only generic information on failures is provided, e.g. information on the dam geometry, protection layer, peak discharge, and time at which the peak discharge occurs. Neither any information on the breach outflow hydrograph, nor detailed geotechnical information is provided by these databases. The format of these databases for levee failures limits the macro-scale analyses and/or the development of empirical based levee breach parameters. Therefore, these databases are not suitable for detailed analysis of processes that initiated failure or for validation of process based models.

As a part of the SAFElevee project, the International Levee Performance Database (ILPD) has been set up to facilitate sharing of data on levee characteristics, failure modes, geotechnical investigations, breach initiation and formation. More specifically, the ILPD has been developed to provide systematically collected datasets on;

- Actual failures during extreme catastrophic events, such as the failure of levees, e.g. the failure of levees in New Orleans, USA [8]

- Failures in large-scale (prototype) experiments, such as dam and levee breach growth experiments in the Netherlands [13]

- General investigations on the performance of flood defense systems, e.g. the case of New Orleans [14] or of the coastal floods in France [15]

- Near failures of levees to determine the proven strength

- Detailed data for validation of individual processes modelled by levee failure models 
- Information on the consequences (e.g. damage, loss of life, flooded area etc.) per extreme event.

The International Levee Performance Database has a three category structure. The first category provides general event information on individual cases of levee failures in a table based information. This generic textual and numeric information on documented (near) failures may include information on the consequences of failures. The second category provides detailed information on failure processes and breach parameters. The detailed information aims to provide more insight in the physical processes and to facilitate rapid analysis of multiple failures and automated validation of breach models. These datasets contain experimental and historical data with time dependent information on the hydrodynamic loading conditions and geotechnical information. The third category provides information on processes related to breaching. Levee breaching is characterized by complicated hydrodynamic, erosion, and geotechnical processes. Hence, process based breach models both have components to deal with the hydrodynamics, erosion, as well as geotechnical processes. The third category contains detailed and valuable information on the physical processes modelled by parts of breach models. The data in the Category- 3 collection aims at validating some of these sub models. With this database structure the SAFElevee project establishes a cooperative data and knowledge platform for governments, researchers and companies in the field of levee safety. It is thereby expected to contribute to more effective and innovative levee reinforcements and large potential cost savings in design and safety assessments.

\section{Levee breaching due to overtopping}

To produce an accurate breach model, it is essential that model approximations are understood and that the model is not applied outside sensible parameter limits. Nowadays, nearly all breach models describe breach processes according to the simplified steps of breach formation described by [13] and [16]. In discussing the stages of breach formation, the levee is described as having a waterside slope, a crest and a landside slope. The waterside slope is defined as the sloping face of the levee at the side of the river or coastal water. The landside slope is defined as the sloping face of the levee at the inland side. The following stages occur, with the possible exception of Stage 3:

1. Levee is stable and functions well.

2. Levee starts to overflow and water percolates into the levee. Material is progressively removed and the landside slope retreats towards the waterside slope.

3. Erosion of the landside slope reaches the waterside slope and the flow slowly starts to increase. The increased hydraulic head over the levee leads to higher flow velocities through the breach, and an increased horizontal flow contraction besides the already present vertical flow contraction.
4. Rapid increase in flow velocity with erosion of the waterside slope and simultaneous widening of the breach. Flow velocities are supercritical.

5. Breach flow becomes affected by the rise of the downstream water level, and/or the fall of the upstream water level, and the breach flow starts to decrease to the point that the flow velocities become so small that the erosion process stops.

These stages have been observed in several large- and small-scale breach experiments [17]. However, differences in breach behavior have been found in the rate, and manner of breach formation. The limits in knowledge relate to the lack of complete understanding of why these differences occur as is exemplified by considering the simple case of breach formation due to overflow of a trapezoidal-shaped flood levee protected by a grass layer.

\subsection{Overflow or overtopping resistance of} grass

Water starts to overflow the levee when the level of water against the levee exceeds the crest level. Grass protection prevents erosion of the levee soil for a period of time, during which the water level may decrease again. To fully assess the breach process as a function of time, it is thus necessary to understand how and when a grass protection layer fails.

In the Netherlands, the Expert Network on Water Safety (ENW) performed several tests on grass erosion under wave attack. ENW [18] reported that evenly distributed and healthy grass provides a cover layer that is highly resistant to erosion. ENW found that grass strength is greatly influenced by the strength of the turf layer. Grass roots of barely-fertilized grass were found to be more erosion resistant than well fertilized grass. However, no explanation is given by ENW on how grass erodes. Nezu and Okamoto [19] studied the profiles of flow over a grass layer, and found that the vertical and horizontal turbulence intensities near the roots were minute, indicating a negligibly small shear stress at the bed. Over the height of the stems, the cumulative shear stress causes a normal tensile force in the stem which is transferred to the soil. This could have a two-fold effect on erosion. First, the tension could cause the stem to snap at the roots leading to a less protected bed. Second, the tension could pull the roots out of the bed. Fluctuations in bed shear stress may thereby loosen the turf layer.

Pollen [20] measured the tensile strength and pull-out forces of grass roots and found that for small diameter roots the breaking forces exceeded the pull-out forces. Larger diameter roots were more likely to be pulled out of the soil. The threshold between the two depends on the shear strength of the soil, the frictional bonds between the root and the soil grains, and the plant-specific tensile strength. Pollen also found that the tensile strength of roots is largely independent of soil moisture content. However, the moisture content of the soil did have an effect on the threshold between roots being pulled out of the soil and breaking of roots. It was observed that as the 
soil dried, the frictional bonds between roots and soil became stronger because the apparent cohesion increased with the matric suction of the soil. It was concluded that the root reinforcement by grass was lowest when the soil moisture content was high and the soil shear strength was low.

Richards [21] found a relationship between soil pore pressure and moisture content. When a soil dries out, its pore pressure becomes progressively negative as the moisture content decreases, positively affecting soil stability. The capillary effect of the soil matrix causes water to flow from regions of high water content (or low matric suction) to regions of lower water content (high matric suction). From the study by Pollen [20], it is possible to conclude that the matric suction of the soil directly affects the erodibility of grass. When a levee overflows, water percolates into the levee, increasing the moisture content of the soil. The resistance of grass to erosion is therefore expected to be dependent on time as well as grass quality. For accurate modelling of the breaching of a grass-covered levee it is not only necessary to address when the grass cover fails but also where along the levee perimeter it fails. Both the load on the grass cover and the grass quality vary along the perimeter of the levee, and so the grass cover does not fail everywhere at once. The order in which the grass cover fails influences the erosion process and hence the breach hydrograph profiles. Current breach models often simplify the failure process of a grass cover by assuming instantaneous failure of the entire grass cover provided certain conditions are met, making the failure of the cover independent of the location. The duration of resistance against failure of a grass cover under certain flow conditions can be estimated using the design chart from Technical Note 71 [22], as presented in Figure 2. The given relationships are not presented as functions of the soil properties and hence the error bars corresponding to each of the relationships are expected to be quite large (though are not provided in Technical Note 71).

However, van Damme et al. [23] recently performed a study to breach initiation under overflow conditions which found orders of magnitude differences in strength of grass when performing an experiment on an existing levee with a clay cover and grass protection. A possible reason for this difference may be that the TN71 tests have been performed on much younger grass covers, which is something that should be taken into account. During the experiment both a wave overtopping simulator and an overflow simulator were used to initiate respectively wave overtopping events and overflow events. It was noted that under overflow conditions whereby the shear stress exerted on the levee was comparable to the peak shear stress during overtopping events, the grass cover did fail during overtopping but did not fail during overflow. This discovery conflicts with the current theories explaining the strength of grass under wave loading and overflow [24][25] but is in agreement with the latest design rules for the maximum allowable mean overtopping discharges of $5 \mathrm{1} / \mathrm{m} / \mathrm{s}$ which have been set in The Netherlands [26].

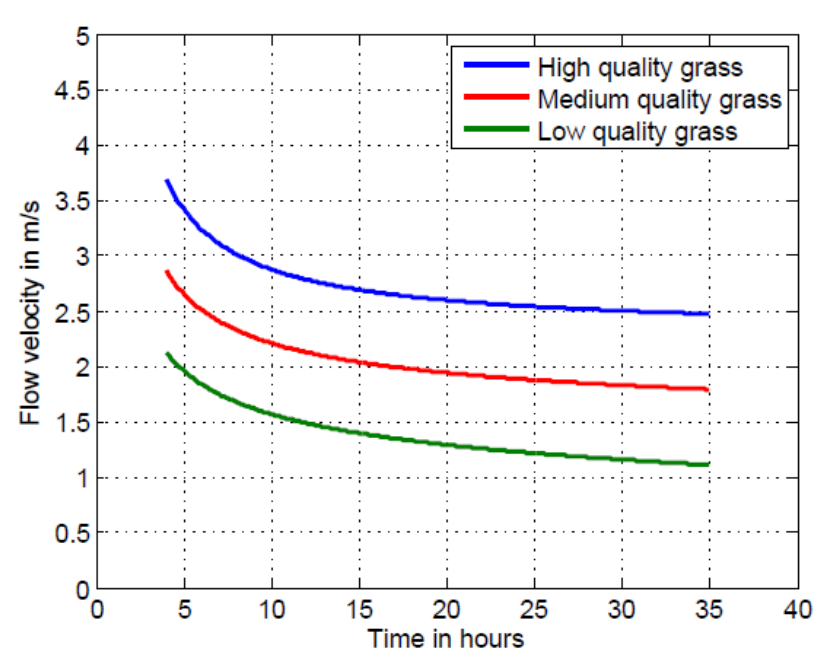

Figure 2. Critical velocities versus time to failure for three quality types of grass covers [22]

\subsection{Determining erosion mechanisms and rates of levee material}

After failure of the grass cover, Stage 2 continues whereby two types of soil erosion processes can occur, the first being surface erosion and the second being headcut erosion [16]. With surface erosion, the levee erodes gradually, whereby sharp gradients in the levee profile are smoothed out. This behaviour was also found by Sametz [27] who performed scale overflow experiments on a levee of $0.365 \mathrm{~m}$ high and made of noncohesive material.

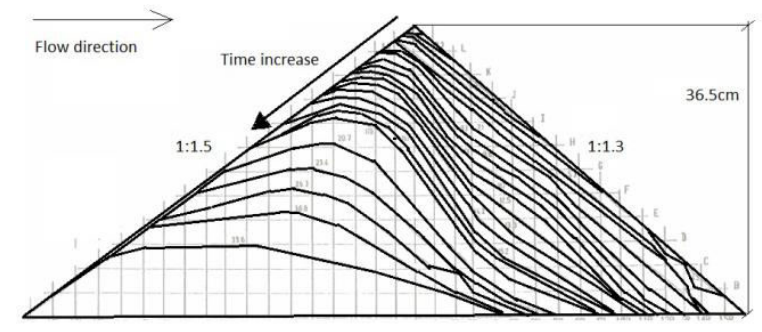

Figure 3. Dam profile development with time for a homogeneous scale levee consisting of non-cohesive material [28]

The time stepping results are given in Figure 3 [28], which clearly shows the reduction in gradients in the levee profile.

Headcut erosion is defined as "... a vertical or near vertical drop in elevation occurring in rill, gully earth spillway and overtopped levees [29]". Zhu et al. [29] performed scale experiments to breaching of levees made of a range of cohesive soils. Figure 4 shows the levee profile development with time for the erosion due to overflow of the test levee constructed of the most cohesive soil. The figure shows a much steeper landside slope gradient for the cohesive levee as is expected in the case of headcut erosion. 


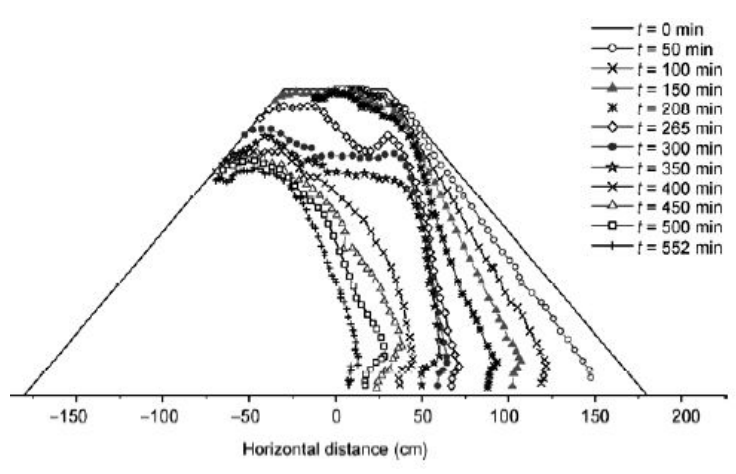

Figure 4. Dam profile development with time for a homogeneous scale levee consisting of cohesive material (Flow direction is from left to right) [29]

Although many studies have examined the physics behind headcut erosion, an understanding of the dynamics of headcut erosion is still inadequate. It is often assumed that surface erosion occurs in case of noncohesive soils, while headcut erosion takes place in case of cohesive soils. However, steep slopes are possible also in case of non-cohesive materials. This was also witnessed during the experiment performed using overflow and wave-overtopping simulators [23]. During this experiment, breach initiation and formation tests were performed using both the overflow and overtopping simulator on a levee consisting of a sandy core and a clay outer layer. The clay outer layer had a mean thickness of $0.5 \mathrm{~m}$. After the grass cover had failed, a headcut type of erosion initiated in both cases. Once the sand layer was reached, the headcut formation continued as massive slope failures were prevented. It was noted that during the headcut formation large slip failures were prevented by the well compacted sandy material. For the sand body in the core to fail, water needed to infiltrate the material in the core. This necessary infiltration of water needed for the soil particles to dilate causes a pressure gradient over the soil. This pressure gradient is only possible when pore suction takes place leading to an increase in effective stresses in the sandy material and preventing rapid slope failures from occurring. Hence the assumption that the non-cohesive material in a levee fails due to surface erosion is an assumption which does not have to be valid. For this, more aspects need to be taken into account.

Another point that is often missed in modelling the surface erosion process is the calculation of the stresses on the levee. The Shallow Water equations and Boussinesq equations are solved to determine the flow velocities down the slope. However, the interested parameters for the case of a levee breach are the shear stress and the erosion rate. In some models the horizontal velocity component is used directly to determine the horizontal bed shear stress component, which in turn is used to determine a downwards displacement of a grid point. Other models also account for the vertical velocity component to derive the bed shear stress on the bed itself. But also in this case, this bed shear stress is used to calculate the vertical displacement of a grid point. Besides analytical models, numerical models usually ignore the horizontal erosion component. In doing so errors are introduced in the model as indicated in Figure 5 .

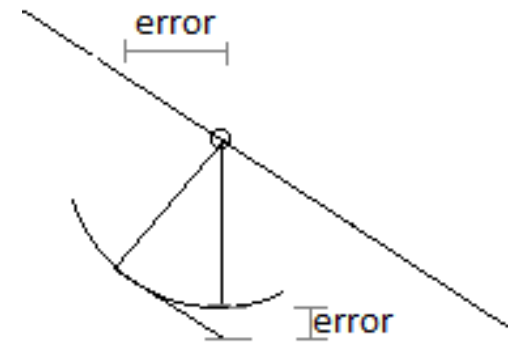

Figure 5. Errors induced due to flow modelling assumptions

When the horizontal erosion component is ignored, the percentile error made in determining the vertical displacement $\left(\right.$ Error $\left._{v}\right)$ is equal to

$$
\text { Error }_{v}=E(1 /(\cos \alpha)-1) \cdot 100 \%
$$

where $E$ is the erosion rate and $\alpha$ is the angle of the landside slope. For landside slope with gradients equal to the internal friction angle of 35 degrees, this error already becomes $22 \%$. As it is generally accepted that the erosion behavior is characterized by the retreat of the landside slope towards the waterside slope, it would be more accurate to account for the horizontal component of the erosion rate $E_{h}$ given by

$$
E_{h}=E(\sin \alpha)
$$

However, numerical models can have difficulty with this as it requires the grid size to be altered. This problem is not encountered by models that are based on analytical solutions like the AREBA model by HR Wallingford ltd [30] and the BRES model by Visser [13].

Transport of levee material is governed by sediment transport processes. The flow continues to accelerate along the landside slope and is thereby predominantly supercritical. Equilibrium flow conditions are not reached and flow acceleration is greatest where the crest meets the landside slope. Due to the continuous acceleration, no equilibrium transport conditions are obtained and the breach erodes due to live scour effects. Within the field of dredging engineering erosion relationships have been developed for high flow velocities. It was noted that under high flow shear stress conditions the infiltration of water into the bed causes for a frictional stress on the particles that contribute to the shear strength of the particles. It was thereby noted that for small particle diameters, the lower hydraulic conductivity caused for a larger stability than in the case of larger particle sizes, making them more resistant to erosion [31][32]. Higher compacted particles would thereby need to dilate more and hence be more resistant to erosion. This would be in line with the findings of Morris [33] who noted that the erodibility of material is dependent on the material texture, moisture content and compaction energy. Sidorchuk [34] stochastically modelled soil erosion and soil deposition using five characteristic stochastic variables: flow velocity, soil cohesion, aggregate size of both native and deposited sediment, and soil consolidation. Sidorchuk emphasizes a 
relatively low increase in erosion rate with respect to the flow velocity, when the driving forces exceeded the stabilizing forces considerably. This is in line with the findings of Van Rhee [31]. However, Sidorchuk found the influence of the variability of soil properties like cohesion, aggregate size and soil consolidation to be less important in determining the erosion rate at high flow energy events. This conflicts with the observations made by Van Rhee who noted that for high flow velocity events the larger particles are more subject to erosion as they more easily dilate.

Morris suggested calculating sediment transport using the erosion equation

$$
E=K_{e}\left(\tau-\tau_{c}\right)^{n}
$$

where $K_{e}$ is the soil erodibility, $\tau$ is the bed shear stress, $\tau_{c}$ is the critical bed shear stress, and $n$ is a power coefficient. The erosion equation relates the shear stress to the erosion rate and therefore is not an equilibrium transport equation. However, shear stress based approaches like these have often not been validated for high flow velocities.

Van Rhee [31] accounts for the effects of dilation by applying a factor to the sediment transport formula of Van Rijn, which is based on a stream power approach. Unlike the shear stress approach, the stream power approach to sediment transport is also valid under supercritical flow conditions. In developing the stream power approach, Bagnold [35] related the transport rate of material to the rate of energy used in transporting materials. Bagnold's relationship that relates streampower to the sediment transport rate is given by

$$
\left(\gamma_{s}-\gamma_{w}\right) / \gamma_{w} E \tan \alpha=\tau V e_{b}
$$

where $\gamma_{s}$ and $\gamma_{w}$ are respectively the specific weight of sediment and water, $\tan \alpha$ is the ratio of the tangential to normal force, $V$ is the average flow velocity, and $e_{b}$ is an efficiency coefficient.

Despite being valid for an extensive range of flow velocities, the sediment transport equations based on the streampower approach are derived for equilibrium sediment transport conditions. However, due to the continuous accelerating flow along the levee perimeter equilibrium sediment transport conditions are not reached in practice. Comparison between the erosion equation and the streampower relationship shows that the erosion equation is a function of the shear stress and the streampower equation is a function of the shear stress multiplied by the mean flow velocity. With the shear stress approximated as a function of the velocity squared, the erosion equation becomes similar to the streampower equation when a power of efficiency $n$ of 1.5 is applied. Hence, the erosion equation is assumed to give a reasonably good approximation under supercritical flow conditions for $n=1.5$. Cohesive sediments have a lower degree of erodibility than non-cohesive sediments. Hence most of the energy dissipated by turbulence is not used to transport sediment particles and a lower value for the power is expected. The power in the erosion equation is thus expected to vary between 1 and 1.5, with a value of 1 more applicable to cohesive sediments, and 1.5 more applicable to loose sediment.

Although the sophistication and predictive capability of breach models has improved over the past 55 years, the models still contain numerous assumptions with corresponding uncertainties. The performance of breach models is thereby often misinterpreted. Morris [17] mentions that models are usually developed and calibrated against a single dataset because of the lack of high quality datasets available for calibration purposes, hence the ability of the model to reproduce the results of the dataset is inherently quite good. It is partially for this reason that under the SAFElevee project an extensive database will be constructed for the purpose of better validating breach models. Moreover, the assessment of model performance by comparing predicted and measured flood hydrographs is also misleading. Because the flood volume is not solely controlled by the rate and size of the breach growth. Current models are able to predict the peak discharge to within an accuracy of 25$30 \%$. Model inaccuracy in predicting the time at which the peak discharge takes place is even worse.

As this section shows, much improvement still needs to be made in the understanding of the breach processes before flood risk predictions can be considered accurate.

\section{Levee failure patterns}

Little is known of what determines levee failure patterns (i.e. number of failures, types and locations) and its important underlying factors. A better understanding of failure mechanisms can enable prediction of failures and can also be used to improve design standards and develop appropriate counter-measures. Through continuous levee monitoring and investigating pre-failure conditions, the SAFElevee project aims to improve the understanding of failure mechanisms and to better predict where they may occur.

As a result of different natural/artificial phenomena, levees can become geotechnically unstable and henceforth cause extensive flooding. Before any sign of failure become visible, the levee may have shown degrees of deformations which could indicate a failure being imminent. More specifically, it has been shown [36] that deformation and failure of levees are correlated. Deformation could thereby be in the vertical, horizontal or transversal directions. Each direction of deformation could be an indicator for a different type of failure.

Levee monitoring systems could be used to improve maintenance strategies and in evacuation planning, thereby reducing flood risk. Flood events with catastrophic results, such as Thailand (2011), Germany (2013), UK (2013, 2014, 2015), Japan (2015) also show that the understanding of levee failure mechanisms and maintenance strategies needs to be improved. Current conventional levee inspection methods consist of expert judgement which consequently results in infrequent, costly, superficial and even qualitative assessments [5][6]. An ability to track the small scale deformations on levees is likely to give a significant contribution to levee inspections. Recent studies show in fact that levee 
deformation monitoring methods based on satellite radar interferometry provide high precision measurements compared to conventional methods [6][36][37][38].

Large flood events, such as New Orleans (2005) with 25 failures and Elbe (2013) with more than 150 failures, are characterized by multiple failures. In case of multiple breaches the impact of flooding may increase significantly [39]. Knowledge of the factors that drive the number of failures and their locations is limited. The SAFElevee project aims to apply satellite radar interferometry to investigate how the spatial and temporal patterns in loading and strength of flood defenses are correlated with actual failure patterns. Particular focus has been given to deformation, as it is an important indicator for a large number of levee failure mechanisms.

\subsection{Levee deformation monitoring using persistent scatterer interferometry (PS-InSAR)}

Radar interferometry has become a widely used geodetic technique to measure the topography and deformations of the Earth's surface over the past few decades [40]. Satellite radar interferometry, also known as Interferometric Synthetic Aperture Radar (InSAR), is a broadly used monitoring technique for investigating surface displacements, such as at buildings, railways, roads and natural movements (e.g. due to volcanos, earthquakes). The main principle is to interfere two radar images in order to obtain information about the surface irregularities [41][42][43]. However, the applicability of this technique is limited due to temporal decorrelation, geometric decorrelation and atmospheric signal delay [42]. These elements result in noisy measurements, especially in green-covered levees, thus reducing the monitoring accuracy.

Several recent researches [42][43][44][45][46] proved that these limitations can be overcome to a certain extent by another technique called Persistent Scatterer Radar Interferometry (PS-InSAR). It aims to reduce problems related to temporal and geometrical correlation and atmospheric effects in order to obtain more accurate results compared to conventional radar interferometry. The profitable characteristics of this technique may be key for a wider applicability of satellite radar interferometry for levee monitoring and for a better understanding of failure mechanisms. One of the main advantages of the PS-InSAR technique can be found in its high precisions with high accuracy (up to mm level) depending on the radar wavelength and signal coherence [38]. Reasonably low-costs, frequent revisits, and high measurement accuracy make this technique a valuable tool for continuous monitoring of levee deformation. Nevertheless, PS-InSAR also shows some limitations such as poor reflections from vegetated areas, highly dependence on many parameters (such as the orientation of the dike, the radar look direction and the amount of acquisitions available from a single track etc.), and difficulty in applying the technique for high displacement rates $(>80 \mathrm{~mm} /$ year) [38]. The possible two types of error (type-I and type-II) in PS identification process should be taken into account in the post-processing of PS-InSAR results. Regarding all these issues, the interpretation of these results requires proper quality assessments with an in-depth perception [36].

One of the major contributions in levee monitoring using PS-InSAR has been done by Hanssen and van Leijen [6]. This study emphasizes that persistent scatterer interferometry is able to provide a dense sampling of water defense systems. It proves that more than $90 \%$ of the primary water defense structures in the Netherlands $(\sim 300 \times 200 \mathrm{~km})$ can be monitored using PS-InSAR (Figure 6a). The authors concluded that with such method, deformations can be monitored using advanced satellite radar technology to obtain weekly updates on levee stability in the Netherlands. In addition to that, they explored the levee deformation at the ring dike of Marken Island, situated north of Amsterdam (Figure 6b). The monitored deformation rate of $13 \mathrm{~mm} / \mathrm{y}$ has led to a maximum subsidence of more than $10 \mathrm{~cm}$ in the time interval of 10 years [6].

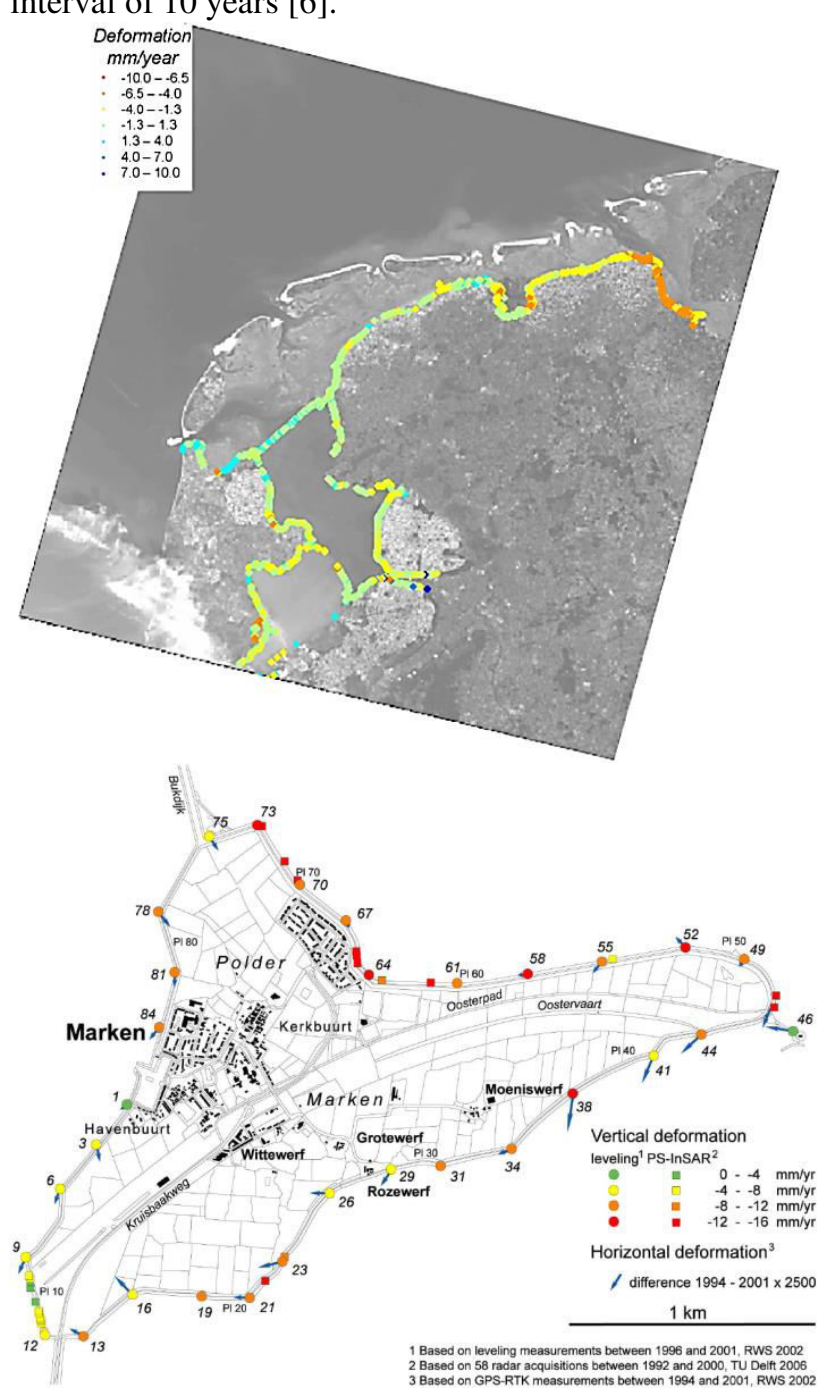

Figure 6. a) Overview of PSI results over water defense systems over the Netherlands [6]. b) Levelling, GPS, and PSI measurements over the levee protecting the former island of Marken [6].

Simultaneously, the POSEIDON project explored the potential of deformation monitoring of water barriers in the Netherlands with the PS-InSAR technique [36]. One of its objectives was to examine the technical feasibility of the method for levee monitoring and its application in 
different case studies. It has been pointed out that the quality of the estimated deformation depends on different factors, such as spatial distribution of the PSs, land cover, rate of motion and linearity of deformation. Complementary contribution was presented by Dixon et al. [37] who used PS-InSAR to monitor the subsidence of the New Orleans area. The highest subsidence rates has been observed between 2002 and 2005 on levees of the Mississippi River-Gulf Outlet canal which breached catastrophically during Katrina Hurricane in 2005 [37]. This study proves that PS-InSAR is not only applicable for land subsidence but also for levee deformation monitoring.

Hydraulic loads are used to define the dimensions and the capacity of flood defense systems. During a certain period of time before the failure event, the correlation between hydraulic loading conditions (e.g. high water level) and deformation measurements is suggested to be examined in order to estimate potential levee failure modes. In case of a defined breach information (e.g. location, length and width etc.), pre-failure deformation data is used to investigate how the levee deformations have changed over time considering the hydraulic conditions and finally caused different sizes of breaches.

In conclusion, levee deformation monitoring using PS-InSAR aims to detect abnormal changes on levees through a continuous levee monitoring. The SAFElevee project aims to investigate the degree of correlation between the loading and deformation data in order to define the required strength of levees and to examine how changes in hydraulic loading conditions effect the deformation of levees.

\section{Summary and future work}

The International Levee Performance Database that will be developed as part of the SAFElevee project serves as: a) a research tool for the SAFElevee project, b) an international collaboration and data sharing platform; and c) an important database for a wide range of end-users, applied for model calibration and validation, and R\&D on models. The database will be available publicly to the scientific and engineering community for research, education and cooperation purposes.

The database forms the foundation stone of the SAFElevee project. As shown in this paper, significant discrepancies still exist between scientific explanations of breach initiation processes and the observable behaviors. Also the accuracy of breach models is still very limited. This highlights the need for further research, a more detailed study of the processes.

Besides focusing on improving the understanding of the physical processes, the SAFElevee project also aims to correlate loading conditions and deformations with past failures. This approach will thereby instigate the development of new design rules with respect to allowable changes of deformation, which in turn could be used in monitoring and maintenance plans. Past studies showed that observations on surface displacements from the available satellites can be used to detect the abnormal changes on levees. However, they mainly focused on the deformation monitoring of small case studies in order to examine the applicability of the PS-InSAR method. The SAFElevee project intends to explore the possibility of using such observations to provide a continuous levee monitoring of wider areas and improved understanding of failure conditions.

\section{References}

1. ABC news (2011, Jan 18). Flood costs tipped to top \$30b. Retrieved from http://www.abc.net.au/

2. European Parliament (2007). Directive 2007/60/EC of the European Parliament and of the council, on the assessment and management of flood risk. Official Journal of the European Union, 288, 27-34

3. Verheij H.J. and Van der Knaap F.C.M. (2002). Modification breach growth model in HIS-OM. WL| Delft Hydraulics Q, 3299, 2002

4. De Moel H. (2012). Uncertainty in Flood Risk. PhD dissertation, $V U$ University Amsterdam

5. Rijkswaterstraat (2001). Hydraulische randvoorwaarden 2001 voor het toetsen van primaire waterkeringen. Technical report, Rijkswaterstraat, DWW, Delft, The Netherlands (in Dutch)

6. Hanssen R.F. and van Leijen F.J. (2008). Monitoring water defense structures using radar interferometry. Radar Conference, RADAR'08, IEEE 1-4

7. Schweckendiek T., Vrouwenvelder A. C. W. M. and Calle E. O. F. (2014). Updating piping reliability with field performance observations. Structural Safety, 47, 13-23

8. Seed R., Bea R., Athanasopoulos-Zekkos A., Boutwell G., Bray J., Cheung C., Cobos-Roa D., Harder L. Jr., Moss R., Pestana J., Riemer M., Rogers J., Storesund R., Vera-Grunauer X., Wartman J. (2008). New Orleans and Hurricane Katrina. III: The 17th Street Drainage Canal. Journal of Geotech. and Geoenviron. Eng., 134(5), 740-761

9. Seed R., Bea R., Athanasopoulos-Zekkos A., Boutwell G., Bray J., Cheung C., Cobos-Roa D., Ehrensing L., Harder L. Jr, Pestana J., Riemer M., Rogers J., Storesund R., Vera-Grunauer X., Wartman J. (2008). New Orleans and Hurricane Katrina. II: The Central Region and the Lower Ninth Ward. Journal of Geotech. and Geoenviron. Eng., 134(5), 718-739

10. Heyer, T. and Horlacher, H. B. (2007). Analyse der Deichbrüche an Elbe und Mulde während des Hochwassers 2002 im Bereich Sachsens "Flussdeiche - Bemessung, Dichtungssysteme und Unterhaltung". In Proceedings of the DWA Seminar, Fulda, Germany (in German).

11. Froehlich D. C. (1987). Embankment-dam breach parameters. In Hydraulic Engineering, Proceedings of the 1987 ASCE National Conference, 570-575

12. Danka J. and Zhang, L. (2015). Dike Failure Mechanisms and Breaching Parameters. Journal of Geotech. and Geoenviron. Eng., 141(9), 04015039

13. Visser P. J. (1998). Breach growth in Sand-Dikes. PhD dissertation, Delft University of Technology

14. Sills G.L., Vroman N.D., Wahl R.E. and Schwanz N.T. (2008). Overview of New Orleans levee failures: lessons learned and their impact on national 
levee design and assessment. Journal of Geotech. and Geoenviron. Eng., 134(5), 556-565

15. Jonkman S.N., Barames V., Blommaart P, de Bruin B., Hardeman B., Kaensap K., van der Meer M., Schweckendiek T., Vrijling J. K. (2012). Post-flood field investigation in the Lower Chao Phraya River Basin, 23 - 27 January 2012, Findings of the Thai Dutch Reconnaissance Team, Final report

16. Morris M., Hassan M., Kortenhaus A., Geisenhainer P., Visser P.J., and Zhu Y. (2009). Modelling breach initiation and growth. FLOODsite Report, 1-127

17. Morris, M., Hanson G., and Hassan M. (2008). Improving the accuracy of breach modelling: Why are we not progressing faster? Journal of Flood Risk Management, 1(3), 150-161

18. Muijs J. A. (1999). Grass cover as a dike revetment. Technical report, Technical Advisory Committee for Flood Defence, Rijkswaterstraat, DWW

19. Nezu I. and Okamoto T. (2010). Simultaneous measurements of velocity and plant motion in openchannel flows with flexible vegetations. Environmental Hydraulics, 2, 209-214

20. Pollen N. (2007). Temporal and spatial variability in root reinforcement of streambanks: accounting for soil shear strength and moisture. Catena, 69(3), 197205

21. Richards L.A. (1931). Capillary conduction of liquids through porous mediums. Journal of Applied Physics, 1(5), 318-333

22. Whitehead E., Bull W., and Schiele M. (1976). A guide to the use of grass in hydraulic engineering practice. Technical report, Construction and Industry Research and Information Association (CIRIA)

23. van Damme M., Ponsioen, L., Herrero, M. (2016). Applying overflow and wave-overtopping simulators in an embankment breach experiment. In FloodRisk2016

24. Hughes S.A. (2011). Adaptation of the levee erosional equivalence method for the hurricane storm damage risk reduction system (HSDRRS). Engineer Research and Development Center Vicksburg Ms Coastal and Hydraulics Lab.

25. Dean R. G., Rosati J. D., Walton T.L. and Edge B. L. (2010). Erosional equivalences of levees: Steady and intermittent wave overtopping. Ocean Engineering, 37(1), 104-113

26. Jonkman, S.N. and Schweckendiek T. (2015). Flood Defences Course Lecture Notes, Delft University of Technology

27. Sametz L. (1981). Beitrag zur Frage der Flutwellenbildung bei progressiven Dammbruchen infolge von Uberstromung. PhD dissertation, Technischen Universitat Graz (in German)

28. Broich K. (1996). Computergestützte Analyse des Dammerosionsbruchs. PhD dissertation, Universität der bundeswehr München, Institut für Wasserwesen (in German)

29. Zhu Y.H., Visser P.J. and Vrijling J. K. (2008). Soil headcut erosion: process and mathematical modeling. In Proceedings in Marine Science, 9, 125-136

30. van Damme M., Morris M.W. and Hassan M. (2012). A new approach to rapid assessment of breach driven embankment failures. FRMRC2 Research Report SWP 4.4, HR Wallingford

31. Van Rhee C. (2010). Sediment entrainment at high flow velocity. Journal of Hydraulic Engineering, 136(9), 572-582

32. Van Rhee C. and Bezuijen A. (1992). Influence of seepage on the stability of a sandy slope. Journal of Geotechnical Eng., 118(8), 1236 - 1240

33. Morris M. (2011). Breaching of earth embankments and dams. PhD dissertation, Open University

34. Sidorchuk A. (2002). Stochastic modelling of soil erosion and deposition. In Proceeding of the 12th ISCO Conference, 136-142

35. Bagnold R. A. (1966). An approach to the sediment transport problem from general physics. General Physics Geological Survey, prof. paper

36. Dentz F., van Halderen L., Possel B., Esfahany S.S., Slobbe C., Wortel T. (2006). On the potential of satellite radar interferometry for monitoring dikes of the Netherlands, technical feasibility study. POSEIDON Project final report, Faculty of Aerospace engineering, TU Delft

37. Dixon T.H., Amelung F., Ferretti A., Novali F., Rocca F., Dokka R., Sella G., Kim S., Wdowinski S., Whitman S. (2006). Subsidence and flooding in New Orleans. Nature Publishing Group, 441(7093), $587-$ 588

38. Clementini C. (2014). A geotechnical based approach for dike monitoring by permanent scatterers interferometry The Case of the Marken Island, The Netherlands. Master Thesis from School of Civil, Environmental and Land Management Engineering, Politecnico Di Milano, Italy

39. Jonkman S.N., Vrijling J.K., Vrouwenvelder A.C.W.M. (2008). Methods for the estimation of loss of life due to floods: A literature review and a proposal for a new method. Natural Hazards, 46(3), 353-389

40. Hanssen R.F. (2001). Radar Interferometry: Data Interpretation and Error Analysis. Kluwer Academic Publishers, 2

41. Bamler R. and Hartl P. (1998). Synthetic aperture radar interferometry. Inverse Problems, 14(4), R1R54

42. van Leijen F. (2014). Persistent Scatterer Interferometry based on geodetic estimation theory. PhD dissertation, Delft University of Technology

43. Ferretti A., Prati C., and Rocca F. (2001). Permanent scatterers in SAR interferometry. IEEE Transactions on Geoscience and Remote Sensing, 39(1), 8-20

44. Berardino P., Fornaro G., Lanari R. and Sansosti E. (2002). A new algorithm for surface deformation monitoring based on small baseline differential SAR interferograms. IEEE Transactions on Geoscience and Remote Sensing, 40(11), 2375-2383

45. Kampes B.M. (2006). The stun algorithm, Radar Interferometry: Persistent Scatterer Technique, Springer, 43-69

46. Hooper A. (2008). A multi-temporal InSAR method incorporating both persistent scatterer and small baseline approaches. Geophysical Research Letters, 35(16) 